\title{
Epistemologias de Nosotras, Feminismos e Teoria da Selva na construção do conhecimento: aportes das mulheres Zapatistas $^{i}$
}

\author{
Lia Pinheiro Barbosa ${ }^{1}$ \\ ${ }^{1}$ Universidade Estadual do Ceará - UECE. Programa de Pós-Graduação em Sociologia. Mestrado Acadêmico Intercampi em \\ Educação e Ensino. Rua Silas Munguba, 1700, Campus do Itapery. Fortaleza - CE. Brasil. \\ Autor para correspondência/Author for correspondence: lia.barbosa@uece.br
}

\begin{abstract}
RESUMO. O presente artigo visa apresentar alguns elementos da epistemologia de nosotras que articula a concepção de luta das mulheres erigida pelas indígenas Zapatistas, em Chiapas, México. Para tanto, apresento o contexto de inserção política das mulheres Zapatistas com o grito de "Já Basta", a Lei Revolucionária das Mulheres e a Insurgência Armada do Exército Zapatista de Libertação Nacional (EZLN), com destaque para os elementos teórico-epistêmicos e políticos que articulam o que denomino um feminismo insurgente, revolucionário, rebelde e autônomo das Zapatistas.
\end{abstract}

Palavras-chave: Zapatistas, Lei Revolucionária de Mulheres, Epistemologia de Nosotras. 


\title{
Epistemologies of Women Ourselves, Feminisms and Theory from La Selve in the construction of knowledge contributions by the Zapatist Women
}

\begin{abstract}
The article aims to present some elements of our epistemology (epistemologia de nosotras) that articulates the conception of women's struggle erected by the indigenous Zapatista in Chiapas, Mexico. For this, I present the context of political insertion of Zapatista women with the cry of "Já Basta" the Revolutionary Women's Law and the Armed Insurgency of the Zapatista Army of National Liberation (EZLN), highlighting the theoretical-epistemic and political elements that articulate what I call an insurgent, revolutionary, rebellious and autonomous feminism of the Zapatistas.
\end{abstract}

Keywords: Zapatism, Revolucionary Law of Woman, Our Epistemology. 


\section{Epistemologías de Nosotras, Feminismos y Teoría de la Selva en la construcción del conocimiento: aportes de las mujeres Zapatistas}

RESUMEN. El presente artículo tiene el objetivo de presentar algunos elementos de la epistemología de nosotras que articula la concepción de lucha de mujeres erigida por las Zapatistas, en Chiapas, México. Para tanto, presento el contexto de inserción política de las mujeres Zapatistas con el grito de "Ya Basta", la Ley Revolucionaria de Mujeres y la Insurgencia Armada del Ejército Zapatista de Liberación Nacional (EZLN), con destaque para los elementos teórico-epistémicos y políticos que articulan lo que denomino un feminismo insurgente, revolucionaria, rebelde y autónomo de las Zapatistas.

Palabras clave: Zapatistas, Lei Revolucionaria de Mujeres, Epistemología de Nosotras. 


\section{Introdução}

O presente artigo tem por objetivo apresentar alguns elementos da epistemologia de nosotras que articula a concepção de luta das mulheres erigida pelas indígenas Zapatistas, em Chiapas, México. O levantamento armado do Exército Zapatista de Libertação Nacional (EZLN), em 01 de janeiro de 1994, constitui um marco na reconfiguração da luta agrária contemporânea dos movimentos indígenas e camponeses na América Latina. O EZLN assume uma identidade política baseada nos seguintes elementos: 1. Descendência direta dos povos maias; 2. Formação política de dupla matriz: das organizações indígenas já existentes na região, e a segunda vinculada à guerrilha maoísta-guevarista; 3 . Inspirados na Teologia da Libertação e 4. Memória histórica da luta política mexicana, a exemplo da Revolução Mexicana (Barbosa, 2016b).

Por se tratar de um movimento originado no campo latino-americano, a insurgência armada do EZLN teve por objetivo explicitar a histórica subalternização dos povos indígenas mexicanos, ademais de reivindicar a revisão do artigo 27 da Constituição Mexicana, referente aos fundamentos básicos do Pacto Agrário, uma das mais expressivas conquistas da Revolução Mexicana de 1910 (EZLN, 1994). Desde então, o Movimento Zapatista consolidou o projeto político autonômico em seus territórios, organizado por Caracóis e Juntas de Bom Governo, instâncias vinculadas ao Governo Autônomo Zapatista (Barbosa, 2016b; 2015).

As mulheres Zapatistas reivindicaram sua inserção política nas instâncias militares e civis do Movimento. Nessa trajetória foram as precursoras da Lei Revolucionária de Mulheres, primeira lei vigente em território Zapatista, além de se posicionarem na assunção de uma concepção teórica própria acerca de sua luta como mulheres, que se fundamenta em uma dimensão epistêmica, a partir do que denomino como uma epistemologia de nosotras.

Para apresentar os fundamentos da epistemologia de nosotras, apresento o contexto de articulação histórica da resistência indígena no enfrentamento da condição colonial e social de serem nomeados como um povo sem alma. Nesse contexto, situo o papel político das mulheres na assunção de uma posição de sujeitos, ponto de partida para contar a própria visão do processo histórico vivenciado milenarmente, e suas interfaces no processo de construção de uma teoria social erigida no marco da práxis 
revolucionária como mulheres e inseridas na luta política do Movimento Zapatista.

\section{De povos sem alma a povos com Razão}

Quem entre nós, povos latinoamericanos e caribenhos, não aprendemos na escola, em particular nos livros de História, que a América foi "descoberta" por homens desbravadores do além-mar? ${ }^{\mathrm{ii}}$ Quem nunca leu, durante o ciclo escolar, que nessas terras "descobertas" habitavam "índios", com formas de vida rudimentares, por não dizer, primitivas e, como se não bastara, povos sem alma, que deveriam ser catequizados com fins de domesticação, uma vez que a catequese constituía, sob a ótica do conquistador, a primeira aurora civilizatória?

A data de 12 de outubro de 1492 se tornou o marco histórico desse discurso da descoberta da América. No Brasil, o dia 21 de abril de 1500. Em ambas, um elemento histórico comum: a imposição, pela via da espada e da cruz, da denominação de índios àqueles que milenarmente habitavam esses territórios, civilizações que possuíam centenas de línguas e uma organização sociocultural, territorial, espiritual e política preexistentes à Conquista. De atribuir-lhes a condição de outro $(s)$, inferiorizando-os em suas racionalidades, em seus corpos, expropriando-os de seus territórios e submetendo-os a toda sorte de opressões, necessariamente violentas, um destino que posteriormente foi compartilhado com os povos africanos escravizados em toda a América.

O modelo educativo implantado pelos Estados nacionais amorteceu, no âmbito da narrativa histórica, o legado da violência epistêmica da Conquista, além de negar a preexistência, na região, de um pensamento ameríndio de ordem milenar (Dussel, 2010). Na conformação dos marcos interpretativos do processo de formação sociocultural do continente, predominou a categorização binária primitivo-civilizado, comum em obras historiográficas, antropológicas, sociológicas e literárias até meados do século XX, uma operação epistemológica baseada nas categorias raça e cultura e que legitimaram um dispositivo taxonômico baseado em identidades opostas (Gómez, 2005). Nessa dicotomia historicamente constituída, é negado que os continentes do sul global, Ásia, África, América Latina e Caribe estejam dotados da razão como atributo humano, conforme problematiza Mongobe Ramose (2002), ao apresentar os fundamentos da Filosofia Africana e a ética do Ubuntu. Trata-se de uma negação intrinsecamente relacionada à Conquista e à determinação dos postulados do 
pensamento ocidental como razão universal. Impôs-se, portanto, uma racionalidade

unilateral,

predominantemente eurocêntrica, que determinou quais os sujeitos que devem ser reconhecidos como dotados da razão e quais categorias, métodos e lugares são considerados legítimos na construção do conhecimento.

$\mathrm{Na}$ contemporaneidade, os povos indígenas $^{\text {iii }}$ interpelam o paradigma da modernidade ocidental capitalista, contrapondo a ele um projeto societário alterno alicerçado em outro paradigma, que nasce do vínculo com a dimensão epistêmica, ontológica e política de seus territórios com o Abya Yala. ${ }^{\text {iv }}$ Esse paradigma, fundamentado em uma cosmovisão, em um ethos, em uma matriz linguística e em uma práxis política que sustenta outras concepções das relações intersubjetivas e com a natureza, portanto, outras práticas de vida erigidas no tecido sócio-comunitário do sumak kawsay, sumak qamaña - bem viver - ou do lekil kuxlejal - vida plena, digna e justa, no horizonte de construção de outros mundos, outros pensamentos.

Nesse marco, ao final do século XX vemos emergir uma significativa articulação regional em torno da Campanha Continental 500 Anos de Resistência Indígena, Negra e Popular
(1989-1992), que expressava a crítica dos movimentos populares da região frente às celebrações oficiais dos 500 anos da Conquista. Esse período é caracterizado pela emergência de lutas emblemáticas, como o surgimento do Movimento dos Trabalhadores Rurais Sem Terra (MST), no Brasil, do levantamento armado do EZLN, no México, da Via Campesina e da Coordenadora Latino-Americana de Organizações do Campo (CLOC), entre outros movimentos sociais do campo em escala regional e nacional. Nutridos pela memória histórica das lutas travadas na região e das rebeliões de caráter revolucionário, esse novo ciclo da luta popular articula uma problemática histórica comum, relacionada ao permanente despojo territorial, à violência epistêmica (Spivak, 2010) e institucional do Estado, que reproduz a ruptura histórica com a racionalidade epistêmica preexistente à Conquista. Portanto, são movimentos que, no processo de defesa de seus territórios, empreendem uma resistência política para que sejam reconhecidos como povos dotados de Razão.

As mulheres têm assumido, no contexto histórico das lutas, um papel vital na defesa da terra, dos seus territórios e, sobretudo, de suas comunidades, amplamente ameaçadas pelo novo padrão 
de acumulação (Federici, 2014). É válido destacar que, para o caso das mulheres indígenas, essa luta incorpora o desafio de forjar-se como sujeito político, a começar em seu próprio caminhar como mulheres, em um movimento reflexivo crítico endógeno-exógeno, em que se problematizam as dimensões históricas do patriarcado e das opressões dele derivadas, seja na esfera institucional do Estado ou no terreno público e privado das relações intersubjetivas do tecido social comunitário. Por conseguinte, pressupõe forjar a própria consciência histórica $\mathrm{em}$ coletivo (em suas comunidades e organizações) e em pares (mulheres e homens) no desafio de descolonizar-se, ou seja, "pensarse desde el centro de nuestro ser, hacer la reflexión teórico-epistémica de la forma como hemos asumido nuestro lugar en el mundo" (Torres, 2013, p. 33). Nesse percurso histórico, as mulheres indígenas tomam a palavra ou, como dizem as mulheres Garífunas de Honduras e Belize, a palavra como via para recuperar a dignidade, um processo em que se revisita a narrativa histórica da colonização e do Estado-nação ocidental moderno para contar e escrever a outra história a partir de suas epistemologias como povos e, em particular, como mulheres que sentem o peso, sobre seus corpos e pensamentos, desse processo civilizatório.

Encontram no caminho outras vozes femininas que também se posicionam como sujeito político, que elaboram um pensamento crítico e teorizam com o compromisso de elaborar abordagens teórico-metodológicas que anseiam por tornarem-se ferramentas interpretativas e de luta em favor da emancipação das mulheres. Certamente se trata de um encontro de vozes com vistas ao diálogo, porém também atravessado por tensões, por justaposições, por imposições, descontinuidades e incompreensões. ${ }^{\mathrm{v}} \mathrm{O}$ feminismo, e logo, os feminismos em plural, constitui uma das categorias que emergem desse exercício conceitual resultante de um processo histórico e político, e que abarca consensos, dissensos e tensões. Para as mulheres indígenas, pensarem-se a partir de si mesmas, de seu caminhar como mulheres que são frutos da longa noite dos 500 anos $^{v i}$ incorpora a reflexão permanente sobre três aspectos centrais: quem tem ocupado o lugar material da reflexão tardia sobre o sujeito $e$ os corpos do feminismo (Vigoya, 2009; Chirix, 2013; Miñoso, 2014); a colonização discursiva e o privilégio epistêmico da prática acadêmica do feminismo ocidental (Mohanty, 2008) e as 
aprendizagens na descolonização do feminismo (Torres, 2013; Castillo, 2014).

No momento histórico de crítica ao feminismo ocidental, é fundamental colocar em perspectiva esses três aspectos, sobretudo para problematizar, conforme nos aponta Chirix (2013), onde subjaz o exercício de poder na escrita das mulheres mestiças e ocidentais sobre as outras mulheres. Do mesmo modo, para delimitar outros parâmetros conceituais e de posicionamento político para as lutas das mulheres que não se autodenominam nos marcos da categoria feminismo, e que reivindicam suas lutas enraizadas às lutas políticas de suas organizações, construídas em coletivo e em pares.

Há, portanto, um debate teóricoepistêmico e político erigido pelas mulheres indígenas de diferentes organizações populares e movimentos sociais, relacionado à premência por criar espaços de formação política e educativa, com o intuito de recuperar e reafirmar suas racionalidades, ao mesmo tempo em que tecem uma concepção teórica própria para suas lutas como mulheres, em um debate contínuo com suas comunidades e no âmbito dos movimentos e organizações nos quais participam. Em toda a América Latina é possível identificar experiências educativas e de formação política dessa natureza, a exemplo daquelas erigidas pelas mulheres maias do México e da Guatemala, das quéchuas da Bolívia e Equador, das mulheres vinculadas à CLOC/LVC, das mulheres Sem Terra, das mulheres do Movimento dos Atingidos por Barragens (MAB) e suas Arpilleras, do Movimento de Mulheres Camponesas (MMC), das mulheres mapuches no Chile e Argentina, entre outras mulheres do campo, das águas, dos quilombos e dos bosques.

No contexto de uma teoria escrita na perspectiva dos movimentos sociais (Barbosa, 2016b), dos feminismos populares, de uma reflexão em torno à justiça de gênero, de transnacionalização do feminismo e num diálogo mediado por outras genealogias, entrelaçadas em matrizes históricas que, por vezes, são enriquecidas por categorias criadas por teóricas feministas, emergem outras composições próprias, que expressam o exercício legítimo de autonomia epistêmica. Para fins da presente reflexão, farei uma aproximação às epistemologias de nosotras a partir da concepção de luta das mulheres Zapatistas, reconhecendo-a como uma teoria social genuína em torno à luta das mulheres e sua apreensão do feminismo, teoria que nomeio metaforicamente de Teoria da Selva. Ao tomar por base os fundamentos epistêmicos dessa teoria, busco outras 
genealogias que aportam, aos feminismos populares, chaves interpretativas próprias, ademais de lançar luzes às tensões e dilemas contemporâneos em torno aos feminismos e à luta das mulheres.

\section{$O$ renascer da longa noite como Mulheres Indígenas, Zapatistas Insurretas}

No poema "GUERRILHA: Substantivo feminino", a poetisa Idylla Ferreira (2016) nos recorda que as guerrilhas, as revoluções, as insurreições, entre outras expressões de resistências e lutas históricas também foram impulsionadas pelos pensamentos, corpos e corações de mulheres. Tal é o caso da conformação das fileiras do EZLN e do levantamento armado, em 1994, em Chiapas, México, que contou com um terço de mulheres indígenas, entre elas, doze em posições de mando, à frente da ocupação militar de seis municípios chiapanecos. Essas mulheres traziam em sua memória ancestral a carga histórica da colonização que condenou a mulher indígena à violência sexual, física e epistêmica, à negação de uma existência digna como ser humano. No processo histórico de subalternização feminina e invisibilidade social, cultural e política das indígenas, não só se negou uma identidade, uma história, uma cultura, como também silenciaram suas línguas maternas e suas vozes, violaram seus corpos, suas virgindades, roubaram seu leite materno, o direito ao território, ao amor, à liberdade, à dignidade.

Nos contextos de colonização, marcados por um profundo racismo, a violência sexual representa uma recolonização do corpo da mulher indígena, no sentido de atribuir-lhe o caráter de extensão territorial circunscrito ao domínio do conquistador, na reafirmação da posse irrestrita como um direito inerente à conquista. Recai sobre os corpos das mulheres indígenas a sentença de tornar-se um corpo Sem Alma, Sem Rosto e Sem Voz.

Além da carga histórica da colonização, outros três fatores impulsionaram a participação política das Zapatistas: 1 . O alto índice de mortalidade infantil de crianças indígenas e suas implicações para a perpetuação da história e da memória dos povos indígenas; 2. O processo interno de mobilização e organização das mulheres, nas comunidades Bases de Apoio Zapatistas, para reivindicar o direito de participação política como mulheres e 3. A modificação do artigo $4^{\circ}$ da Constituição Mexicana, que determina a supremacia dos homens no acesso do dispositivo legal relacionado aos direitos garantidos pela lei de usos e costumes indígenas. Conforme essa lei, é 
vetada às mulheres $\mathrm{o}$ direito de propriedade sobre a terra, seja por compra ou herança. Portanto, há uma invisibilidade jurídica com relação às mulheres indígenas, um mecanismo de reprodução da negação histórica de direitos, estratégia jurídica intrínseca à lógica estrutural de apropriação dos territórios e que tem, como um dos principais pilares, o processo de erosão dos direitos "tradicionais" das mulheres com respeito a sua participação nos sistemas de terras comunais (Federici, 2014).

Ao processo de organização da autonomia Zapatista em seus territórios (Barbosa, 2015), o governo mexicano respondeu com o incremento da Guerra de Baixa Intensidade (GBI), uma resposta imediata à luta autonômica zapatista. A contrainsurgência torna-se um instrumento da política etnocida do Estado, caracterizada pela ação violenta do exército federal e de paramilitares nos territórios indígenas. Na GBI, as mulheres se tornam um objetivo estratégico, recaindo mais uma vez sobre seus corpos as atrocidades que atravessam os contextos de guerra: privações, execuções e violência sexual. O Massacre de Acteal ${ }^{\mathrm{vii}}$ é exemplo de uma ação contrainsurgente brutalmente violenta, com o intuito de provocar uma resposta militar do EZLN e, dessa maneira, ter o álibi para atacar militarmente as comunidades Zapatistas.

$\mathrm{Na}$ ocasião do massacre, as mulheres indígenas participantes do Congresso Nacional Indígena $(\mathrm{CNI})^{\text {viii }}$ conclamaram à solidariedade com Acteal e emitiram um comunicado de denúncia da violação de direitos humanos e da prática da violência sexual contra as mulheres indígenas como uma estratégia da guerra contrainsurgente. Atualmente denominado "Acteal Sítio de la Conciencia y Casa de la Memoria y de la Esperanza", o local celebra, anualmente, a memória dos seus mártires. A memória de Acteal incorpora os sentidos da insurgência das mulheres Zapatistas. No relato das sobreviventes do massacre se destaca o depoimento de Micaela, com 11 anos de idade à época, que escutou os paramilitares ordenarem "há que matar as sementes", referindo-se às mulheres grávidas e ao fruto de seu ventre fecundo.

O ritual misógino sobre os corpos das mulheres indígenas se cumpria: as grávidas tinham seus ventres abertos por facões e seus filhos arrancados e lançados de um facão a outro, em um pinguepongue macabro; com as outras mulheres indígenas assassinadas, desnudavam-nas, abriam suas pernas e metiam um pau pela vagina! $!^{\mathrm{ix}} \mathrm{Na} \mathrm{GBI}$, matar a semente significa matar o embrião da resistência indígena, insurgente, rebelde e autônoma. 
A dialética da guerra nos corpos das mulheres torna-se o cerne do debate político das mulheres Zapatistas. Durante o I Encontro Intercontinental pela Humanidade e Contra o Neoliberalismo, na Mesa "Mulheres e sociedade civil excluída", reconheceu-se o patriarcado como fundamento do neoliberalismo e que imprime suas marcas na expropriação territorial impulsada pelo capital transnacional na ofensiva contra seus territórios. As Zapatistas enfatizavam a urgência histórica na compreensão das raízes históricas do patriarcado e em situar o gênero como uma categoria central a ser incorporada à crítica do neoliberalismo como projeto político (EZLN, 1996).

Pese a ofensiva da GBI em seus territórios, a autonomia Zapatista avança e permanece em desenvolvimento, contando com a inserção das mulheres que, paulatinamente, galgam espaços de participação política. À exceção daquelas que estão no EZLN e as milicianas, as demais Zapatistas desempenham cargos no Governo Autônomo, nas Juntas de Bom Governo (JBG), em outras áreas de trabalho nos Municípios Rebeldes Autônomos Zapatistas, como parteiras e curandeiras (com medicina fitoterápica ou com quiroprática), como Promotoras de Saúde, Promotoras de Educação, Promotoras de Agroecologia,
Coordenadoras Gerais de Zona e como Tercio Compas $^{\mathrm{x}}$ (EZLN, 2013).

$\mathrm{O}$ primeiro documento produzido pelas Zapatistas foi a Lei Revolucionária de Mulheres, primeira lei vigente em seus territórios e do código legal da Justiça Autônoma Zapatista. ${ }^{\mathrm{xi}}$ Essa lei é considerada um marco normativo dos direitos e aspirações das mulheres indígenas, como também de posições de sujeito (Miñoso, 2014) no despertar de uma subjetividade feminista zapatista, que é tecida no transcurso da rearticulação comunitária prévia à Insurgência Armada, condição imprescindível na conformação do sujeito histórico-político Zapatista (Barbosa, 2015). Assim, no âmbito das demandas gerais da comunidade, as Zapatistas começam a inserir as demandas específicas das mulheres, em um movimento dialético de permanência câmbio (Millán, 1996), ou seja, superar o patriarcado próprio do costume, da tradição. A Lei Revolucionária de Mulheres preconiza: ${ }^{\text {ii }}$

En su justa lucha por la liberación de nuestro pueblo, el EZLN incorpora a las mujeres en la lucha revolucionaria sin importar su raza, credo, color o filiación política, con el único requisito de hacer suyas las demandas del pueblo explotado y su compromiso a cumplir y hacer cumplir las leyes y reglamentos de la revolución. Además, tomando en cuenta la situación de la mujer trabajadora en México, se incorporan sus justas demandas de igualdad y 
justicia en la siguiente LEY REVOLUCIONARIA DE MUJERES: Primero.- Las mujeres, sin importar su raza, credo, color o filiación política, tienen derecho a participar en la lucha revolucionaria en el lugar y grado que su voluntad y capacidad determinen. Segundo.- Las mujeres tienen derecho a trabajar $\mathrm{y}$ recibir un salario justo. Tercero.- Las mujeres tienen derecho a decidir el número de hijos que pueden tener y cuidar. Cuarto.- Las mujeres tienen derecho a participar en los asuntos de la comunidad y tener cargo si son elegidas libre y democráticamente. Quinto.- Las mujeres y sus hijos tienen derecho a ATENCION PRIMARIA en su salud $y$ alimentación. Sexto.- Las mujeres tienen derecho a la educación. Séptimo.- Las mujeres tienen derecho a elegir su pareja y a no ser obligadas por la fuerza a contraer matrimonio. Octavo.- Ninguna mujer podrá ser golpeada o maltratada físicamente ni por familiares ni por extraños. Los delitos de intento de violación o violación serán castigados severamente. Noveno.- Las mujeres podrán ocupar cargos de dirección en la organización y tener grados militares en las fuerzas armadas revolucionarias. Décimo.- Las mujeres tendrán todos los derechos y obligaciones que señala las leyes y reglamentos revolucionarios.

Com a criação da Lei Revolucionária de Mulheres, as Zapatistas começaram a assumir cargos civis e militares. $\mathrm{O}$ inciso sexto da Lei Revolucionária - as mulheres têm direito à educação - foi fundamental no fortalecimento da formação educativa e política das Zapatistas. Reivindicar o direito de estudar vai muito além do acesso à escola, uma vez que anseia a ruptura histórica com o racismo epistêmico, uma construção social que assentou as bases de uma hierarquia social erigida por matrizes raciais e étnicas (Vigoya, 2008; Chirix, 2013), e que consolidou, no plano simbólico-ideológico, a supremacia branca. Sob a base desta supremacia, se ergueram as posições de dominação e subordinação, as opressões, os atributos de estigma e o controle sobre os corpos das mulheres indígenas. Assim, reivindicar o direito à educação é um ato político de subversão da dialética colonial e de autoridade epistêmica por meio da Pedagogia da Palavra (Barbosa, 2018), ou seja, tomar a palavra como mulheres indígenas, o direito de fala e de uma fala posicionada em 500 anos de luta.

$\mathrm{Na}$ perspectiva da reivindicação dos direitos, a aprendizagem do espanhol (castilla) possibilita enlaçar-se com o mundo "kaxlan" (mestiço), para evitar marginações, abusos e "poder se defender". Por outro lado, a demanda coletiva por essa aprendizagem é suscitada em virtude da intensificação da GBI em suas comunidades, o que requer um domínio da linguagem imperante nos organismos jurídicos para fins de denúncia e de exigência de justiça (Barbosa, 2015).

Está claro, portanto, que a castilla é a língua que media o discurso institucional do Estado, sob o julgo do patriarcado, e que define hegemonicamente a concepção 
de justiça e de direitos na perspectiva do privilégio branco, uma construção histórica inerente ao projeto colonial na América Latina e que o transcende, ao reproduzir-se na normativa do direito constitucional do Estado-nação moderno e sua capacidade de veto aos direitos às populações indígenas e, em particular, às mulheres indígenas. Nessa direção, educar-se possibilita o entendimento dos códigos jurídicos, suas ambiguidades, ao mesmo tempo em que se questiona a autoridade epistemológica do Estado e da racionalidade ocidental moderna. Aliás, com o aprendizado da castilla, as mulheres Zapatistas disputam a linguagem jurídica, ao fundar as bases da Justiça Autônoma Zapatista, com a outorga da primeira lei vigente em seus territórios a Lei Revolucionária de Mulheres construída coletivamente por elas, em suas línguas maternas, porém escrita em espanhol, para demarcar sua posição de sujeito e sua autonomia epistêmica, como pioneiras na elaboração de um marco jurídico para o enfrentamento do entronque patriarcal (Galindo, 2013); uma lei que, paulatinamente, se tornou um documento de referência para a luta das mulheres no México e no mundo.

Outro fator de extrema importância na aprendizagem da castilla estava relacionado com a formação política e militar no EZLN: algumas insurgentas relatam que, por se tratar de um exército clandestino conformado por indígenas de diferentes etnias, portanto, de diferentes línguas, o espanhol se tornou a língua comum, tanto para o estudo dos manuais de estratégia militar, como também para receber as instruções de mando. ${ }^{\text {xiii }}$ No I Encontro das Mulheres Zapatistas com as Mulheres do Mundo, ${ }^{\text {xiv }}$ outra insurgenta relata:

Estando en la montaña aprendimos muchas cosas. Si no sabíamos leer y escribir, hablar la castilla, nos enseñaba a nosotras los compañeros. Todo lo que no aprendimos en nuestra casa, ahí aprendimos todo en la montaña. Estando como insurgenta es nuestra obligación aprender todo tipo de trabajo ... Aprendimos lo político, lo militar y lo cultural.

A Lei Revolucionária de Mulheres torna público um processo de elaboração conceitual próprio das Zapatistas e que fundamenta as bases epistêmicas de sua teoria social em torno da luta das mulheres, uma Teoria da Selva, locus de sua insurgência como mulheres e de uma práxis revolucionária.

\section{Epistemologia de nosotras e a Teoria da Selva na práxis política das Zapatistas}

A consolidação do Sistema Educativo Rebelde Autônomo Zapatista de Libertação Nacional (SERAZ-LN) constituiu um processo político central na defesa da dimensão epistêmica do projeto 
autonômico Zapatista e no posicionamento político de sua palavra, de sua voz como movimento indígena anticapitalista e antisistêmico (Barbosa, 2015). Desde a Primeira Declaração da Selva Lacandona e no conjunto das seis declarações emitidas pelo EZLN, os documentos, comunicados, consignas políticas, canções, poemas, contos, entre outros escritos, as e os Zapatistas fortaleceram uma narrativa política enraizada em um sentido metafórico e metateórico que expressa a profundidade epistêmica da cosmovisão e das línguas maias articulada à construção e consolidação de um projeto político de caráter emancipatório.

Não é à toa que na trajetória política do Movimento Zapatista há o posicionamento pela recuperação, valorização e fortalecimento da língua enquanto expressão do seu pensamento, da sua racionalidade e de seu posicionamento sociocultural e político como movimento indígena. Há, portanto, uma transição da guerra das armas pela guerra desde a palavra, compreendendo a palavra construída em uma perspectiva histórica, intrinsecamente vinculada à memória de mais de 500 anos em resistência (Barbosa, 2015). Nas palavras do EZLN (1996): ${ }^{\mathrm{xv}}$

Nuestra palabra, nuestro canto y nuestro grito, es para que ya no mueran más los muertos. Para que vivan luchamos, para que vivan cantamos ... La flor de la palabra no muere, aunque en silencio caminen nuestros pasos. En silencio se siembra la palabra. Para que florezca a gritos se calla. La palabra se hace soldado para no morirse en el olvido. Para vivir se muere la palabra, sembrada para siempre en el vientre del mundo. Naciendo y viviendo nos morimos. Siempre viviremos. Al olvido sólo regresarán quienes rinden su historia. Aquí estamos. No nos rendimos. Zapata vive y, a pesar de todo, la lucha sigue. Desde las montañas del Sureste Mexicano.

As mulheres indígenas da América Latina constroem sua teoria a partir de marcos epistêmicos próprios, e em sintonia com o desejo de que seja uma flor da palavra que não morre, mas que se semeia e renasce na memória histórica de suas lutas. Para o caso das Zapatistas, destacam-se três matrizes epistêmicas fundamentais para a compreensão da Teoria da Selva que fundamenta a concepção de sua própria luta como mulheres, elaborada em sua práxis educativo-política: 1. Dimensão epistêmica da cosmovisão e da língua maia; 2. Dimensão epistêmica do território; 3. Dimensão epistêmica da complementaridade.

\section{Dimensão Epistêmica da Cosmovisão e Língua Maia}

A racionalidade Zapatista se fundamenta na dimensão epistêmica da matriz linguística e da cosmovisão maia, 
que se tornam o fio condutor dos saberes compartilhados na vida comunitária e no contexto de sua luta política. Assim, no processo de consolidação do pensamento teórico-epistêmico e político Zapatista, alguns conceitos das línguas maias ${ }^{\mathrm{xvi}}$ são recuperados como pilares da construção de conhecimento e de uma teorização que problematiza concepções de mundo legitimadas historicamente pela ciência ocidental moderna. Vejamos alguns exemplos a seguir.

O o’tan - coração; stael e o ch'ulel alma-espírito-consciência: conforme o antropólogo Intzín (2013) estes são conceitos da língua maia tseltal que traduzem a base da cosmovisão maia e os processos de sociabilidade comunitária e com a natureza. O o’tan, enquanto núcleo da cosmovisão maia-tseltal, dimensiona a apreensão da vida e do posicionamento individual e coletivo no mundo, orientando-se a partir de uma lógica racional de sentir-pensar e sentir-saber. Para os povos indígenas maias significa construir um pensamento em estreito vínculo com o coração.

Com base nesses conceitos, o atributo da razão, de uma filosofia própria, não exclui as emoções, os sentimentos, as espiritualidades que também são elementos constituintes dos seres humanos e de seu convívio entre si e com os outros seres, com o plano material e imaterial da vida. Em outras palavras, antes de converter-se em uma operação abstrata da razão, os pensamentos e os saberes passam, primeiramente, pela mente e pelo coração, ou seja, a palavra se coraçona na perspectiva Zapatista, uma expressão da racionalidade que pode ser interpretada como uma dimensão do ser-estar-pensarsentir com e no mundo (Barbosa, 2014).

tik - nosotros, nós: o conceito tojolabal tik ou nosotros é considerado o cerne da racionalidade Zapatista na consolidação de uma identidade e subjetividade política. Constitui o conceito que estrutura a definição de participação política, de democracia à luz da autonomia Zapatista. Conforme Lenkdersdorf (2002, p. 31), o tik:

... enfatiza una identidade grupal y no individual ... En el intercambio grupal de ideas, cada uno de los participantes habla del NOSOTROS y no del yo ... cada uno de los participantes habla y respecta esa relación que llamamos 'NOSÓTRICA' y que orienta todos hacia un acuerdo, en lugar que cada uno hable por sí mismo, convencido de sus ideas para jalar a los demás en dirección suya.

A ação nosótrica delimita os princípios da sociabilidade comunitária e a posição de sujeito ocupada por cada membro da comunidade. Conforme o Subcomandante Insurgente Marcos (EZLN, 1996, p. 67): 
La única forma en que la gente podía asegurarse seguir adelante era juntándose con el otro. Por eso la palabra junto, la palabra nosotros, la palabra unidos, la palabra colectivo, marca la palabra de los compañeros. Es una parte fundamental, diría yo, la columna vertebral del discurso zapatista.

'ab’ $i \quad$ escutar: conforme Lenkersdorf (2008) este conceito representa a escuta, entretanto, uma escuta que incorpora as formas de sentir, de pensar desde a perspectiva do outro, ou seja, em uma relação de reciprocidade do nosotros. A escuta do outro pressupõe a capacidade de colocar-se no lugar do outro, ao mesmo tempo em que se concebe uma escuta para compreender os argumentos que estruturam o posicionamento daquele a quem se escuta. Portanto, o processo da escuta preconiza uma capacidade de apreensão das palavras e dos sentimentos expressos pelo outro ou outros. O ' $a b^{\prime} i$ constitui um conceito central para a compreensão dos sete princípios Zapatistas: 1. Baixar e não subir; 2. Convencer e não vencer; 3 . Construir e não destruir; 4. Representar e não suplantar; 5. Propor e não impor; 6. Obedecer e não mandar e 7. Servir e não servir-se.

ja 'altsili - tudo vive: na cosmovisão maia tudo tem vida, tudo vive e essa perspectiva apresenta, em si mesma, uma ruptura epistêmica com a racionalidade ocidental que define a natureza entre a viva e a morta. Assim, a dimensão da vida incorpora aos seres humanos, mas também a fauna, a flora, as águas, as montanhas, as cavernas, os astros, etc. (Lenkersdorf, 2008). Do ponto de vista epistêmico, considerar que tudo vive é reconhecer que não há uma cisão entre vida e morte.

p’ij yo'tan - é único o teu coração: pressupõe uma autonomia pessoal, do ser como único em sua singularidade; também pode ser interpretado como um processo de integração coletiva, da capacidade de alcançar consensos e de integrar-se no âmbito da comunidade (Paoli, 2003).

De igual maneira é fundamental recuperar o Popol Wuj - livro sagrado dos povos K'ich'e Maia da Guatemala, ${ }^{\text {xvii }}$ uma referência central na recuperação da memória ancestral no processo de construção do conhecimento no âmbito das experiências educativas e políticas dos movimentos indígenas da América Central. Nesse livro sagrado encontramos as ideias cosmogônicas sobre a origem da vida e dos seres humanos, o calendário maia e a organização do tempo, as concepções sobre os territórios, as posições de sujeito (anciãos, mulheres, homens e crianças) e as relações intersubjetivas no âmbito da vida comunitária, com a natureza e com o Abya Yala (Asturias \& González, 1965; Odile, 1999; DeLaVega, 2016). Do ponto 
de vista da conformação de um ethos identitário e político, recupera-se do Popol Wuj o mito originário da criação do ser humano, de serem homens e mulheres do milho (hombres y mujeres del maíz), ou seja, aqueles que foram feitos do milho (Asturias \& González, 1965).

Os Zapatistas estão entre aqueles que recuperam a dimensão epistêmica do Popol Wuj na elaboração de seus documentos políticos, em suas consignas políticas, na sua literatura, na sua expressão estética e nos materiais didáticos utilizados na Educação Autônoma. A identidade sociocultural afirmada no Popol Wuj possui uma dimensão epistêmica que permite ao Movimento Zapatista reafirmarse como homens e mulheres do milho, apreendendo em sua narrativa política a defesa dos seus territórios e de todos os bens naturais nele existentes, compreendidos como uma herança milenar dos povos maias (Barbosa, 2014; 2015). Nesse caso, o milho é reconhecido para além de um alimento, pois incorpora uma apropriação epistêmica da cosmovisão e estabelece outra relação intersubjetiva entre os seres humanos e seus territórios no Abya Yala. Essa apreensão epistêmica do Popol Wuj é trabalhada pedagogicamente no SERAZ-LN, sobretudo na área da História e das Línguas, na Educação Primária Rebelde Autônoma Zapatista.
Particularmente no livro didático Arte en Rebeldía (2006), há um trecho explícito do Popol Wuj que faz referência ao mito originário dos homens e mulheres do milho, seguido da imagem de uma espiga de milho e do seu nome em tseltal - ixim (EZLN, 2006, p. 88):

He, aquí, pues, el principio de cuando se dispuso a hacer al hombre, y cuando se buscó lo que debía entrar en la carne del hombre. Y dijeron los Progenitores, los Creadores y los Formadores “... que aparezca el hombre, la humanidad, sobre la superficie de la tierra". Así dijeron. Y así encontraron la comida y ésta fue la que entró en la carne del hombre creado del hombre creado, del hombre formado; ésta fue su sangre, de ésta se hizo la sangre del hombre. Así entró el maíz [en la formación del hombre] por obra de los Progenitores.

Além do material didático utilizado nas escolas autônomas, vemos as referências diretas do mito originário do Popol Wuj nos diversos murais existentes nos Caracóis e nas Comunidades Bases de Apoio Zapatista, ademais dos bordados feitos pelas Zapatistas. Aliás, é importante destacar a dimensão pedagógica dos bordados elaborados pelas mulheres na construção e transmissão dos saberes e do conhecimento entre as gerações. Os bordados retratam a história da luta política Zapatista e, em particular, das mulheres Zapatistas, a construção da autonomia em seus territórios, entre outros conteúdos 
formativos, a propósito da etnomatemática, da agroecologia e da cosmovisão maia, o que evidencia a estética política da autonomia Zapatista (Barbosa, 2014; 2015).

\section{Dimensão Epistêmica do Território}

Historicamente, o território é compreendido como locus de resistência e de conformação de um ethos identitário e é parte constitutiva da narrativa política dos movimentos indígenas e camponeses latino-americanos em defesa da terra, da natureza, dos bens comuns e no reconhecimento do território como espaço de reprodução social da vida, lugar de criação e ressignificação das relações socioculturais e de poder. É válido destacar que essa compreensão do território interpela diretamente àquela vinculada à ótica do europeu colonizador à época da conquista, isto é, de uma terra nullius, terra de ninguém, de um território inabitado, portanto, propenso à colonização, à expropriação e exploração irrestritas, à instauração da propriedade privada por meio de direitos adquirido pelos países colonizadores, e que infringiam a soberania das civilizações e nações que já habitavam os diferentes territórios do Abya Yala.

Inclusive, no atual contexto de desenvolvimento do capitalismo neoliberal em sua modalidade extrativista, a dialética da territorialização e da desterritorialização se configura como a nova modalidade da luta de classes (Veltmeyer, 2018). Portanto, recuperar o prisma histórico da terra nullius nos permite analisar a ânsia do capital transnacional por territórios sem gente, à plena disposição dos megaempreendimentos que caracterizam o (neo)extrativismo, sobretudo na América Latina.

Nessa perspectiva, recupero a concepção de etnoterritorialidade simbólica (Barabás, 2003), categoria que expressa a apropriação indígena dos territórios e que se contrapõe às denominações atribuídas pelo Estado, a exemplo de "agrário", "municípios", entre outras, que atribuem um sentido de ocupação e divisão territorial distinto e, por vezes, até antagônico à concepção milenária do território. Ao se definir autarquias com jurisprudência própria, há um maior controle institucional do Estado sobre os territórios e se instauram mecanismos de regulação territorial favoráveis à sua expropriação pelo setor privado vinculado aos megaempreendimentos.

O estudo desenvolvido por Barabás apresenta exemplos pré-coloniais e coloniais, decorrentes de fontes etnohistoriográficas, que demonstram as 
relações estabelecidas pelas comunidades indígenas com seus territórios a partir de sua cosmovisão, portanto, uma abordagem histórica milenária da territorialidade indígena. Dela, emergem conceitos fundamentais relacionados à configuração dos territórios em períodos pré-hispânicos e que foram reproduzidos milenarmente na inter-relação intersubjetiva estabelecida com a natureza.

Nessa linha, os territórios podem ser reduto de lugares sagrados, por exemplo, serras, montanhas, grutas ou outras formas naturais dotadas de sacralidade, espaços ritualísticos vinculados à fertilidade, à natalidade, à vida e à morte (Odile, 1999; Barabás, 2003). Ou ainda, de um atributo político aos territórios defendidos por comunidades em luta contra o capital transnacional (Veltmeyer, 2018). É fundamental destacar que são as mulheres do campo, das águas e das florestas, as principais defensoras da concepção do território como espaço de vida.

As mulheres indígenas e camponesas guardiãs das sementes, as curandeiras, as xamãs, entre outras, guardam consigo a memória biocultural das sabedorias tradicionais (Toledo \& Barrera-Bassols, 2008), o que tem garantido a preservação de sementes nativas, a fertilidade dos solos vinculados aos quintais produtivos, entre outros saberes diretamente relacionados à agricultura tradicional camponesa. Por outro lado, essas mesmas mulheres incidem politicamente, ao tecerem a crítica ao modelo de desenvolvimento hegemônico vinculado ao capital transnacional e, em contraposição a esse modelo, impulsionarem a agroecologia como matriz produtiva e projeto político.

\section{Dimensão da Complementaridade}

Outra matriz epistêmica do pensamento Zapatista está representada pelo conceito de lajan lajan 'aytik, que significa estar em pé de igualdade, ou ainda, formamos juntos comunidade de iguais(Lenkersdorf, 2008). Argumenta Marcos (2011) que no mundo indígena não existem categorias mutuamente excludentes, uma vez que os fundamentos cosmológicos mesoamericanos se baseiam no princípio do equilíbrio. Assim, a dualidade é o que caracteriza a natureza dos seres, entre eles, o gênero feminino e masculino. A fluidez do gênero se faz presente na filosofia mesoamericana, e o processo de construção do pensamento evita promover uma divisão por meio da exclusão. A dualidade masculino-feminino é básica na cosmologia maia e seu vínculo se dá por meio do conceito de complementaridade $\quad-\quad$ entre homem/mulher, entre ser humano/natureza - isto é, uma forma de interpretação do ser 
(mulher e homem) em inter-relação com o universo em perspectiva complementaria.

Dessa maneira, na construção do pensamento mesoamericano há a fusão do feminino e do masculino em um princípio singular, porém polarizado, no qual as divindades se concebiam em pares, a partir do princípio da complementariedade, com o intuito de manter as duas forças em equilíbrio. Se retomarmos a Lei Revolucionária de Mulheres, vemos claramente o princípio da dualidade complementária, ao se exigir o direito de participação política igualitária como mulheres, "sin importar su raza, credo, color o filiación política, tienen derecho a participar en la lucha revolucionaria en el lugar y grado que su voluntad y capacidad determinen". Em diferentes relatos das mulheres Zapatistas ${ }^{\text {xviii }}$ encontramos a reivindicação de ser reconhecidas como iguais, em construir a autonomia para as mulheres e os homens no caminhar lado a lado, caminhar em pares (caminar parejo). Assim, o princípio do caminhar em pares, em pé de igualdade é o fundamento da proposta feminista das mulheres Zapatistas e o acordo é a mediação pedagógica e política para seu alcance.

As dimensões apresentadas da epistemologia de nosotras - cosmovisão, língua, territorialidade e complementariedade $\quad-\quad$ constituem elementos nodais do posicionamento político e de elaboração teórica das Zapatistas, intimamente relacionados a uma dimensão epistêmica da cosmovisão, da língua maia e da práxis política em defesa de seus territórios. Na realidade, as Zapatistas exercem sua autonomia epistêmica ao explicitar a forma como constroem sua subjetividade política e sua luta como mulheres: "Nosotras no usamos la palabra feminismo, porque de por si siempre hablamos lucha de las mujeres. Y hay diferentes palabras para decir lo mismo, porque entendemos que es lo mismo, pero lo decimos de nuestra manera, que es diferente."xix

A autonomia epistêmica das Zapatistas, em dizer sua palabra, que está em consonância com outros delineamentos teórico-políticos das feministas, mas dito de forma diferente, tem suscitado articulações ao afirmar, por exemplo, "que el zapatismo coincide con algunos elementos de las tesis del feminismo, pues propone una nueva ética del poder, que no sea patriarcal" (EZLN, 1996: 158). Entretanto, as aproximações entre Zapatistas e teóricas feministas também estão atravessadas por campos de tensão, descontinuidades, ou mesmo rupturas e silenciamentos. Para compreender esse terreno, é fundamental retomar os três aspectos que apresentei ao início do artigo, 
por ser fruto de reflexões construídas nesses interstícios e que embasam o posicionamento das Zapatistas: o sujeito e os corpos do feminismo; a colonização discursiva e o privilégio epistêmico do feminismo ocidental e a descolonização do feminismo.

$\mathrm{O}$ privilégio e a autoridade epistêmicos têm se apresentado como elementos nodais nas tensões estabelecidas entre as Zapatistas e as teóricas feministas.

\section{No Primeiro Encontro Internacional,} Político, Artístico, Esportivo e Cultural de Mulheres que Lutam, realizado em março de 2018, no Caracol IV - Morelia, as Zapatistas explicitaram essa tensão, ao afirmarem, "porque no solo los hombres, también hay mujeres de las ciudades que nos desprecian, que porque no sabemos de la lucha de mujeres, porque no hemos leído libros donde las feministas explican cómo debe ser y tantas cosas que dicen y critican sin saber cómo es nuestra lucha." A palavra coletiva das Zapatistas evidencia a carga simbólica e material do racismo epistêmico, muitas vezes presente no labor teórico de "emancipar as mulheres" e que, em realidade, está suscetível de reproduzir um colonialismo, expresso em um etnocentrismo intelectual, de imposição de uma teoria que se pretende universal e que demarca, sob critérios categoriais do ocidente, por vezes a-históricos, quais os elementos que definem uma luta que, necessariamente, deve ser denominada feminista, quem de fato é feminista ou quais lutas podem ser consideradas realmente como feministas.

A crítica ao colonialismo das práticas discursivas do feminismo hegemônico tem sido amplamente realizada por outras teóricas feministas, que se posicionam na defesa de outros feminismos desde o Abya Yala. $^{\mathrm{xx}}$ Entretanto, mesmo no reconhecimento de outras genealogias da luta das mulheres, ainda perdura uma estrutura teórico-metodológica que enquadra a análise e, portanto, delimita o sujeito e os corpos do feminismo. No contexto latino-americano, as Zapatistas, as mulheres da CLOC, as mulheres do Feminismo Comunitário, entre outras, são enfáticas, ao afirmar que necessitam um feminismo útil para a luta dos povos.

Nesse sentido, situo a reflexão apresentada por uma militante da CLOC/LVC, ${ }^{\text {xxi }}$ ao problematizar que o enquadramento teórico almejado pelas feministas impede um enriquecimento do feminismo por uma tendência ao veto a outras expressões de luta das mulheres. Para essa mesma militante, a urgência por definir um marco teórico, em suas palavras, como um feminismo póscolonial, descolonial, decolonial, conduz a um labirinto conceitual incompreensível 
para as mulheres que constroem sua luta no campo popular. As Zapatistas corroboram com esta reflexão, ao mencionarem que são muitas palavras novas, que nem sempre conseguem entender, ${ }^{\text {xii }}$ mas que talvez estejam dotadas do mesmo sentido atribuído por elas em sua luta como mulheres indígenas. Portanto, há um caminho sinuoso, ou mesmo um fosso no diálogo entre as Zapatistas e as teóricas feministas, decorrente de uma suposta autoridade epistêmica.

Entretanto, é válido destacar que existe um esforço de autorreflexão crítica entre as teóricas feministas no intuito de pensar os desafios para a descolonização do feminismo, no sentido de superar o etnocentrismo intelectual e as lógicas de poder que invisibilizam, ou mesmo desconhecem, a existência das mulheres indígenas e camponesas (Castillo, 2014). Trata-se do reconhecimento de que é necessário ampliar o entendimento das lutas, transpondo o campo individual ao coletivo, para um exercício da escuta, no aprender a escutar e a olhar, ensinamento epistêmico das e dos Zapatistas, sem a pretensão de uma escuta averiguadora ou orientadora de como ser / tornar-se feminista. Ao contrário, de uma aprendizagem, de uma comunhão com as teorias construídas por outras mulheres em processos políticos intrinsecamente articulados com o campo popular.

Nesse exercício da escuta, é fundamental compreender os elementos que embasam uma epistemologia de nosotras, para situar o posicionamento político das Zapatistas na construção de sua luta como mulheres, na defesa dos territórios e na consolidação da autonomia como princípio e projeto político. Como expressão desse exercício do aprender $a$ escutar e a olhar das teóricas feministas, destaco alguns trechos da "Carta a la Comandanta Ramona", escrita por Mercedes Olivera, reconhecida lutadora social e intelectual feminista mexicana, lida durante o "Conversatorio Miradas, Escuchas, Palabras: ¿Proibido pensar?”, realizado em abril de 2018, no CIDECIUniversidad de la Tierra, em San Cristóbal de las Casas, Chiapas. A carta traz sua reflexão logo após participar do Primer Encuentro Internacional, Político, Artístico, Deportivo y Cultural de Mujeres que Luchan:

Para nosotras que vivimos afuera fue maravilloso verlas actuando como una sola, percibir su ritmo de tolerancia $\mathrm{y}$ harmonia ... $\mathrm{y}$ recibiéndonos con una escucha ejemplar ... Las jóvenas Zapatistas nos dieron a las viejas y nuevas feministas una lección teórica y práctica del feminismo revolucionario que pratican en sus caracoles, sin la necesidad siquiera de darle el nombre. Desde la convocatória dirigida a las mujeres 
que luchan, ejercieron su sabedoria: ninguna se sintió excluída y llegamos todas las que luchamos ... La lucha de las mujeres es mundial y Morelia se universalizo con esta convocatoria. Nuestra fuerza personal se engrandeció con esta fuerza colectiva harmonizada por las Zapatista. Y que impresionante, Ramona, que estuvimos presentes mujeres con posiciones diferentes, compartiendo sin conflicto. Todas pudimos expresarnos, sentirnos unidas $\mathrm{y}$ fuertes porque todas luchamos, ciertamente de muy diferentes maneras, Ellas, nuestras anfitrionas, siguen tu ejemplo, Ramona, nos oyeron con gran respeto y sin reclamos.

\section{Nossa luta é pela vida: reflexões finais}

Quando as Zapatistas afirmam “crecí en la resistencia y rebeldía Zapatistas de nuestras abuelas, mamás y hermanas mayores ... Aquí nacimos. Aquí crecimos. Aquí luchamos. Aquí vivimos,"xxiii colocam em evidência a dimensão da práxis revolucionária que não se limita às palavras de um discurso, de um livro, mas sim tomando as armas e construindo a autonomia na luta cotidiana em seus territórios. O grito de “Já Basta!” é o início do caminho, custe o que custe. ${ }^{\text {xxiv }}$ Nessa direção, as Zapatistas nos ensinam que são mulheres que constroem sua teoria e sua práxis política enraizadas em uma epistemologia de nosotras que confere sentido ao que definem como território, como sociabilidade comunitária e à tessitura dos acordos estabelecidos em coletivo e em pares no âmbito da vida cotidiana e na construção da autonomia Zapatista. Essa epistemologia de nosotras enraíza-se em um feminismo insurgente, revolucionário, rebelde e autônomo das Zapatistas e em uma dialética que se traduz em lutar como se vive e viver como se luta.

A Lei Revolucionária de Mulheres, de 1993, os documentos, os comunicados, a assunção de cargos e os trabalhos coletivos demonstram um processo contínuo de construção da teoria e da práxis revolucionária, rebelde e autônoma das Zapatistas, que muito aporta à compreensão de que a luta de mulheres está vinculada a um projeto político amplo, de caráter antipatriarcal e anticapitalista. Nesse contexto, é fundamental descolonizar o feminismo e fortalecer os feminismos e as lutas das mulheres em uma perspectiva popular, em que seja útil para as lutas, como reiteradas vezes nos ensinam as Zapatistas, mas também outras mulheres que realizam sua luta no campo popular.

Ao posicionar sua autonomia epistêmica, as Zapatistas nos ensinam o coração epistêmico de uma Teoria da Selva, que abrange sua concepção política da luta como mulheres indígenas. Em suas palavras:

Sabemos que en ese bosque, en ese monte, hay muchos árboles que son diferentes. Y lo sabemos que hay, por 
ejemplo, ocote, pino, hay caoba, hay cedro, hay bayalte y hay muchos tipos de árboles. Pero también sabemos que cada pino y cada ocote no es igual, sino que cada uno es diferente ... Bueno, aquí estamos como un bosque o como un monte. Todas somos mujeres. Pero lo sabemos que hay de diferentes colores, tamaños lenguas, culturas, profesiones, pensamientos y formas de lucha. Pero decimos que somos mujeres y además que somos mujeres que luchan. Entonces somos diferentes, pero somos iguales.

Ser bosques de mulheres é romper com os riscos de uma fragmentação de nossas lutas; é respeitar-nos em nossas diferencias, mas também ter unidade política para combater o inimigo comum que é o patriarcado e o capitalismo em nossos territórios, seja no campo ou na cidade. É evitar um enquadramento teórico para silenciar ou medir nossa capacidade de interpretação da realidade. Ao contrário, é fundamental que se fortaleça um diálogo de saberes em que aprendamos entre todas dos legados das teorias e práxis revolucionárias historicamente erigidas por mulheres que entretecem cotidianamente os caminhos da resistência.

O “Já Basta!" das Zapatistas foi um grito em defesa da vida, da vida dos seus filhos, de outros filhos, em defesa da vida de ventres permanentemente ameaçados pela GBI e a brutal violência sobre os corpos das mulheres indígenas, na permanente denúncia do feminicídio e do desaparecimento cotidiano das mulheres, uma chaga aberta para muitas famílias mexicanas. Também uma reafirmação dos corpos das mulheres como territórios de resistência; na defesa de seus territórios como espaços de vida, e na luta incessante contra a desterritorialização, característica da disputa territorial com o capital transnacional. Nesse sentido, a Comandanta Miriam me relata: ${ }^{\mathrm{xxv}}$

Entonces decidimos hacer el encuentro para hacer florecer semillas, para fortalecer a nosotras, para mostrar a nosotras, las mujeres, que tenemos el valor y sabemos solitas, así como los hombres también pueden solitos. Las más jóvenes, pues, están mejor porque ya saben leer, escribir. Nosotras no sabíamos leer, escribir, hablamos poco la cartilla, pero hoy ellas ya saben y tienen otras tareas porque ahora tienen que saber de la lucha de las mujeres más allá de Chiapas, de México, en otros lados.

Nesse processo de fazer florescer sementes vemos a transcendência teórica, política e epistêmica de LUTAR PELA VIDA, tarefa revolucionária das Zapatistas. Finalizo este escrito com a estética da resistência Zapatista (Barbosa, 2015) que, na noite do dia 08 de março de 2018, no marco do Encontro Internacional Mulheres que Lutam, ascenderam uma luz e nos deixaram a seguinte mensagem:

Esta pequeña luz es para ti. Llévala, hermana y compañera. Cuando te sientas sola. Cuando tengas miedo. 
Cuando sientas que es muy dura la lucha, o sea, la vida. Préndela de nuevo en tu corazón, en tu pensamiento, en tus tripas. Y no la quedes, compañera y hermana. Llévala a las desaparecidas. Llévala a las asesinadas. Llévala a las presas. Llévala a las violadas. Llévala a las golpeadas. Llévala a las acosadas. Llévala a las violentadas de todas las formas. Llévala a las migrantes. Llévala a las explotadas. Llévala a las muertas. Llévala y dile a todas y a cada una de ellas que no está sola, que vas a luchar por ella. Que vas a luchar por la verdad y la justicia que merece su dolor. Que vas a luchar porque el dolor que carga no se vuelva a repetir en otra mujer en cualquier mundo. Llévala y conviértela en rabia, en coraje, en decisión. Llévala y júntala con otras luces. Llévala y, tal vez, luego llegue en tu pensamiento que no habrá ni verdad, ni justicia, ni libertad en el sistema capitalista patriarcal. Entonces, tal vez, nos volvamos a ver para prender fuego al sistema. Y entonces, hermana y compañera, ese día que será noche, tal vez podremos decir contigo: bueno, pues, ahora sí vamos a empezar a construir el mundo que merecemos $y$ necesitamos.

\section{Referências}

Asturias, M.A., \& González, J. M. (1965). Popol Vuh o Libro de Consejos de los Indios Quichés. Buenos Aires: Edición Losada.

Barabás, A. (2003). Diálogos con el Territorio. Simbolizaciones sobre el espacio en las culturas indígenas de México. Colección Etnografía de México. México: CONACULTA-INAH.

Barbosa, L. P. (2014). Educación y lucha autonómica en la Voz Zapatista: aportes de la Pedagogía del Sentir-Ser, Sentir-Pensar, Sentir-Saber. Dossier Movimientos Sociales y Educación. Revista Educación y Cultura, 105, 21-27.

Barbosa, L. P. (2015). Educación, resistencia y movimientos sociales: la praxis educativo-política de los Sin Tierra y de los Zapatistas. México: LIBRUNAM.

Barbosa, L. P. (2016a). Educación, resistencia y conocimiento en América Latina: por una teoría desde los movimientos sociales. Revista De Raíz Diversa, 3(6), 45-79.

Barbosa, L. P. (2016b). Educação rebelde e autônoma na práxis revolucionária Zapatista. In Rebuá, E., \& Silva, P. (Orgs.). Educação e Filosofia da Práxis: reflexões de início de século (pp. 48-79). Rio de Janeiro, RJ: Letra Capital.

Barbosa, L. P. (2018). Mulheres Zapatistas e a Pedagogia da Palavra no tecer da outra educação. In Castro, A. M., \& Machado, R. C. (Orgs.). Estudos Feministas, Mulheres e Educação Popular (pp. 25-48). São Paulo. SP: Liber Ars.

Castillo, R. A. H. (2014). Algunos aprendizajes en el difícil reto de descolonizar el feminismo. In Millán, M. (coord.) Más allá del feminismo: caminos para andar (pp. 183-211). México: Red de Feminismos Descoloniales.

Chirix, E. (2013). Cuerpos, poderes y políticas: mujeres mayas en un internado católico. Guatemala: Ediciones Maya' Na'oj.

Christlieb, P. F. (2014). Justicia Autónoma Zapatista. Zona Selva Tseltal. México: Ediciones Autónom@s.

DeLaVega, M. L. (2016). Comunidad y Estado: el territorio Ixil en el Quiché, Guatemala. (Tese de Doutorado). 
Universidad Nacional Autónoma de México, Ciudad de México, México.

Dussel, E. (2010). Transmodernidad e interculturalidad. Interpretación desde la Filosofía de la Liberación. In Mondragón, A., \& Monroy, F. (Coords.). Interculturalidad. Historias, experiencias y utopías (pp. 39-70). México: Plaza y Valdes.

Ezln (1994). Documentos e Comunicados. Tomo 1. México: ERA.

Ezln (1996). Crónicas Intergalácticas. Primer Encuentro Intercontinental por la Humanidad y contra el Neoliberalismo. Chiapas: Planeta Tierra.

Ezln (2013). Participación de las Mujeres en el Gobierno Autónomo. Cuaderno de Textos del Primer Grado del Curso de "La Libertad según l@s Zapatistas. Chiapas: EZLN.

Ezln (2014). Arte en Rebeldía. Chiapas: Planeta Tierra.

Federici, S. (2014). La inacabada revolución feminista. Mujeres, reproducción social y lucha por lo común. Colombia: Ediciones desde Abajo.

Ferreira, I. S. S. (2016). Guerrilha: Substantivo feminino. In MST (Org.). Versando Rebeldia (pp. 53-54). São Paulo, SP: Setor de Educação.

Galindo, M. (2013). No se puede descolonizar sin despatriarcalizar. Teoría y propuesta de la despatriarcalización. Bolívia: Mujeres Creando.

Gómez, S.C. (2005). Ciencias sociales, violencia epistémica y el problema de la invención del otro. In E. Lander (Org.). Colonialidad del saber: eurocentrismo y ciencias sociales (pp. 145-161). Buenos Aires, Argentina: CLACSO.
Hernández, M. A. L. (2004). Encuentros en los senderos del Abya Yala. Quito, Equador: Ediciones Abya Yala.

Intzín, J. L. (2013). 'Ich'el ta muk': la trama en la construcción del Lekil kuxlejal (vida plena-digna-justa). In Torres, G. M., Intzín, J. L., Marcos, S., \& Hernández, C. O. (Coord.). Senti-pensar el género. Perspectivas desde los pueblos originarios (pp. 101-110). México: Red Interdisciplinaria de Investigadores de los Pueblos Indios de México / Red de Feminismos Descoloniales.

Lenkdersdorf, C. (2002). Filosofar en clave Tojolabal. México: Editora Porrúa.

Lenkersdorf, C. (2008). Aprender a escuchar. Enseñanzas maya-tojolabales. México: Plaza y Vades.

Marcos, S. (2011). Mujeres, indígenas, rebeldes, zapatistas. México: Ediciones Eón.

Millán, M. (1996). Las zapatistas de fin de milenio. Hacia políticas de autorepresentación de las mujeres indígenas. Chiapas, 3, 19-32.

Miñoso, Y. E. (2014). Etnocentrismo y colonialidad en los feminismos latinoamericanos: complicidades y consolidación de las hegemonías feministas en el espacio transnacional. In Miñoso, Y. E., Correal, D. G., \& Muñoz, K. O. (Eds.). Feminismos, epistemología y apuestas descoloniales en Abya Yala (pp. 309-324). Colombia: Editorial UC, 2014.

Mohanty, C. (2008). De vuelta a 'Bajo los ojos de Occidente': la solidaridad feminista a través de las luchas anticapitalistas. In Naváz, L. S., \& Castillo, R. A. H. (Coords). Descolonizar el Feminismo: teorías y prácticas desde los márgenes (pp. 404-467). Madrid: Cátedra. 
Odile, M. M. (1999). El poder de las hijas de la luna: sistema simbólico y organización social de los lacandones. México: Plaza y Valdés.

Paoli, A. (2003). Educación, autonomía y lekil kuxlejal. Aproximaciones sociolingüísticas a la sabiduría de los tzeltales. México: UAM.

Ramose, M. (2002). African Philosophy through Ubuntu. Harare: Mond Books Publisher.

Santos, L. E. S., \& Valverde, M. C. (2003). Historiografía maya de origen indígena (siglos XVI-XIX). In Galván, J. R. R. (Org.). Historiografía Mexicana. Volumen I. Historiografía novohispana de tradición indígena (pp. 133-167). México: UNAM.

Spivak, G. (2010). Pode o subalterno falar? Belo Horizonte, MG: Editora da UFMG.

Torres, G. M. (2013). Mujeres MayasKichwas en la apuesta por la descolonización de los pensamientos y corazones. In Torres, G. M., Intzín, J. L., Marcos, S., \& Hernández, C. O. (Coord.). Senti-pensar el género. Perspectivas desde los pueblos originarios (pp. 27-62). México: Red Interdisciplinaria de Investigadores de los Pueblos Indios de México / Red de Feminismos Descoloniales.

Toledo, V. M., \& Barrera-Bassols, N. (2008). La memoria biocultural. La importancia ecológica de las sabidurías tradicionales. Barcelona, Madrid: Icaria Editorial.

Veltmeyer, H. (2018). Resistance, class struggle and social movements in Latin America: contemporary dynamics, The Journal of Peasant Studies, DOI: $\underline{10.1080 / 03066150.2018 .1493458}$
Vigoya, M. V. (2008). La sexualización de la raza y la racialización de la sexualidad en el contex to latinoamericano. Memorias del Primer Encuentro Latinoamericano y del Caribe. La sexualidad frente a la sociedad. México, D. F. Recuperado em 15 de março, 2018, de http://www.derechoshumanos.unlp.edu.ar/ assets/files/documentos/la-sexualizacionde-la-raza-y-la-racializacion-de-la$\underline{\text { sexualidad.pdf }}$

${ }^{\mathrm{i}} \mathrm{O}$ presente artigo apresenta dados de pesquisa desenvolvida junto ao Grupo de Trabalho "Cuerpos Territorios y Resistencias", vinculado ao Conselho Latino-Americano de Ciências Sociais (CLACSO).

ii À exceção do México, Bolívia, Equador e Peru que inserem, no currículo escolar, a história das civilizações anteriores à Conquista.

iii Em realidade, esse debate é aberto por todo o sul global. Entretanto, delimitarei, para fins do presente escrito, o posicionamento dos povos indígenas da América Latina.

iv Abya Yala é o nome pelo qual hoje se conhece a extensão territorial do continente denominado América e que literalmente significa terra em pleno amadurecimento ou terra de sangue vital. Esse nome foi dado pelos povos Kuna no Panamá e Colômbia, e a nação Guna Yala do atual Panamá antes da chegada de Cristóvão Colombo e dos europeus (Hernández, 2004).

v Algumas delas serão apresentadas ao longo do escrito.

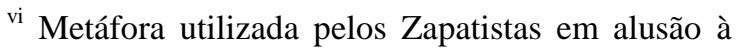
Conquista.

vii No dia 22 de dezembro de 1997, paramilitares atacaram a comunidade de Acteal, no município de San Pedro Chenalhó, Chiapas, e assassinaram 44 indígenas, entre eles, 04 mulheres grávidas, além de crianças, que se encontravam em jejum e oração pela paz na capela da comunidade.

viii Principal instância de representação das organizações e movimentos indígenas no México.

ix Este depoimento, entre outros, foi registrado em diário de campo em 2010 e 2011, quando participei das atividades em memória do massacre, em Acteal. 
x Tercio compas são todas aquelas que se especializam nas técnicas audiovisuais e que se responsabilizam pela documentação e sistematização de todas as atividades desenvolvidas nos territórios Zapatistas ou outros espaços públicos em que o Movimento Zapatista desempenhe alguma participação.

${ }^{x i} \mathrm{O}$ estudo de Christlieb (2014) reúne o conjunto de instruções, leis, acordos, medidas e regulamentos Zapatistas.

xii Publicado em 1993 no "El Despertador Mexicano”, órgão informativo do EZLN (1994).

xiii Os relatos podem ser vistos no documentário "Las compañeras tienen grado", disponível em: https://www.youtube.com/watch?v=inCcx2sbToo\& $\mathrm{t}=31 \mathrm{~s}$

xiv Documentário "El derecho de ser feliz". Disponível em: https://www.youtube.com/watch?v=aWkKwdGKtx E

${ }^{\mathrm{xv}}$ IV Declaração da Selva Lacadona.

${ }^{\mathrm{xvi}}$ Nem todos serão apresentados devido à extensão do escrito.

xvii O Popol Wuj é uma coletânea das antigas tradições dos povos K'ich'e da Guatemala. Escrito após a conquista espanhola, o Popol Wuj é parte constitutiva da chamada historiografia colonial da tradição maia e é considerado um legado do pensamento indígena da América Central, sobretudo pela transcrição da história oral que preservou a memória dos fatos passados das comunidades indígenas dessa região (Santos \& Valverde, 2003).

${ }^{\text {xviii }}$ Recomendo o documentário acerca do Encontro das Mulheres Zapatistas com as Mulheres do Mundo e o documento EZLN (2013).

${ }^{\text {xix }}$ Relato de uma Zapatista, membro da Junta de Bom Governo, em diálogo realizado durante Primeiro Encontro Internacional, Político, Artístico, Esportivo e Cultural de Mulheres que Lutam.

${ }^{\mathrm{xx}}$ Vide Torres et. al. (2013); Espinosa-Miñoso et. al. (2014).

xxi Em diálogo realizado durante o Primeiro Encontro Internacional, Político, Artístico, Esportivo e Cultural de Mulheres que Lutam.

${ }^{x x i i}$ Em diálogo realizado com mulheres Zapatistas durante o Primeiro Encontro Internacional, Político,
Artístico, Esportivo e Cultural de Mulheres que Lutam.

xxiii Primeiro Encontro Internacional, Político, Artístico, Esportivo e Cultural de Mulheres que Lutam.

${ }^{\text {xxiv }}$ Expressão muito utilizada nos pronunciamentos das e dos Zapatistas.

xxv Em diálogo realizado durante o Primeiro Encontro Internacional, Político, Artístico, Esportivo e Cultural de Mulheres que Lutam.

\section{Informações do artigo / Article Information}

Recebido em : 30/05/2018

Aprovado em: 28/08/2018

Publicado em: 23/12/2018

Received on May 30th, 2018

Accepted on August 28th, 2018

Published on December 23th, 2018

Contribuições no artigo: A autora foi responsável pela elaboração, análise e interpretação dos dados; escrita e revisão do conteúdo do artigo, e aprovação da versão final publicada.

Author Contributions: The author was responsible for the designing, delineating, analyzing and interpreting the data, production of the manuscript, critical revision of the content and approval of the final version published.

Conflitos de interesse: A autora declarou não haver nenhum conflito de interesse referente a este artigo.

Conflict of Interest: None reported.

\section{Orcid}

Lia Pinheiro Barbosa

http://orcid.org/0000-0003-0727-9027

\section{Como citar este artigo / How to cite this article}

APA

Barbosa, L. P. (2018). Epistemologias de Nosotras, Feminismos e Teoria da Selva na construção do conhecimento: aportes das mulheres Zapatistas. Rev. Bras. Educ. Camp., 3(4), 1128-1155. DOI: http://dx.doi.org/10.20873/uft.2525-4863.2018v3n4p1128

ABNT

BARBOSA, L. P. Epistemologias de Nosotras, Feminismos e Teoria da Selva na construção do conhecimento: aportes das mulheres Zapatistas. Rev. Bras. Educ. Camp., Tocantinópolis, v. 3, n. 4, set./dez., p. 1128-1155, 2018. DOI: http://dx.doi.org/10.20873/uft.2525$\underline{4863.2018 v 3 n 4 p 1128}$ 